\title{
High-temperature elasticity of magnesioferrite spinel
}

\author{
Sytle M. Antao $\cdot$ Ian Jackson - Baosheng Li $\cdot$ \\ Jennifer Kung · Jiuhua Chen · Ishmael Hassan · \\ Robert C. Liebermann · John B. Parise
}

Received: 31 October 2006/Accepted: 28 February 2007/Published online: 22 March 2007

(C) Springer-Verlag 2007

\begin{abstract}
The elastic moduli of magnesioferrite spinel, $\mathrm{MgFe}_{2} \mathrm{O}_{4}$, and their temperature dependence have been determined for the first time by ultrasonic measurements on a polycrystalline specimen. The measurements were carried out at $300 \mathrm{MPa}$ and to $700^{\circ} \mathrm{C}$ in a gas-medium high-pressure apparatus. On heating, both the elastic bulk $\left(K_{\mathrm{S}}\right)$ and shear $(G)$ moduli decrease linearly to $350^{\circ} \mathrm{C}$. By combining with extant thermal-expansion data, the values for the roomtemperature $K_{\mathrm{S}}$ and $G$, and their temperature derivatives are as follows: $K_{0}=176.3(7) \mathrm{GPa}, G_{0}=80.1(2) \mathrm{GPa},\left(\partial K_{\mathrm{S}} /\right.$ $\partial T)_{P}=-0.032(3) \mathrm{GPa} \mathrm{K}^{-1}$ and $(\partial G / \partial T)_{P}=-0.012(1) \mathrm{GPa}$ $\mathrm{K}^{-1}$. Between 350 and $400^{\circ} \mathrm{C}$, there are abrupt increases of $1.4 \%$ in both of the elastic moduli; these closely coincide with the magnetic Curie transition that was observed by thermal analyses at about $360^{\circ} \mathrm{C}$.
\end{abstract}

S. M. Antao $(\square)$

Advanced Photon Source, Argonne National Laboratory, Argonne, IL 60439, USA

e-mail: sytle.antao@anl.gov

\section{Jackson}

Research School of Earth Sciences, Australian National University, Canberra, ACT 0200, Australia

B. Li · J. Chen - R. C. Liebermann - J. B. Parise Mineral Physics Institute and Department of Geosciences, Stony Brook University, Stony Brook, NY 11794-2100, USA

\section{J. Kung}

Department of Earth Sciences, National Cheng Kung University, 1 University Road, Taiwan 70101, Taiwan, R.O.C

I. Hassan

Department of Chemistry, University of the West Indies,

Kingston 7, Jamaica
Keywords Magnesioferrite $\cdot$ High-temperature studies · Ultrasonic · Elasticity

\section{Introduction}

Determining crystal structures and elasticity of minerals constituting the Earth is an important goal in mineral physics. Variations in $\mathrm{P}$ and $\mathrm{S}$ wave velocities with depth are amongst the few experimental observables available. The velocity-depth profiles place powerful constraints on proposed models of the Earth's interior, and interpretation of the observed variation requires knowledge of the crystal structures and elastic properties of the candidate minerals, and their phase transitions as a function of $P$ and $T$. Experimental determination of these parameters with pressure-temperature-composition-time $(P-T-X-t)$ can be inferred from quench studies, extrapolated from studies at high pressure alone, or determined directly in situ. While there are a large number of important studies documenting variations of sound velocities for a particular composition with changing crystal structure as a function of $P$ and $T$; the number of studies addressing changes in sound velocities as a function of electronic, magnetic and site ordering at different $P$ and $T$ are far fewer (e.g., Liebermann and Banerjee 1971; Liebermann and Remsberg 1988, and references cited therein). This, despite considerable evidence that these changes, often considered second order effects, can give rise to considerable discontinuities in velocities with changes in magnetic ordering, spin state and site ordering (Hazen and Yang 1999; Li et al. 2007; Sturhahn et al. 2005).

Numerous studies have been carried out on spinels because of their chemical and structural simplicity, their geological importance, and their use as geothermometers, 
geobarometers, and geospeedometers (e.g., O'Neill and Wall 1987; Sack 1982). Members of the spinel family, especially the ferrites, offer rich opportunities to explore the effects of variation in elasticity with changes in magnetic properties, spin state and cation disorder. $\mathrm{MgFe}_{2} \mathrm{O}_{4}$ spinel, the object of this study, is particularly interesting since its thermal expansion and changes in crystal structure are well known from previous work (Antao et al. 2005a, b) and because this spinel also has a well-documented magnetic transition at about $360^{\circ} \mathrm{C}$, which provides an ideal opportunity to observe the effect of this magnetic transition on ultrasonic velocities.

\section{Experimental}

\section{Specimen description}

The magnesioferrite sample was synthesized from equimolar amounts of dried reagent-grade oxides: $\mathrm{MgO}$ (slightly excess) and $\mathrm{Fe}_{2} \mathrm{O}_{3}$, in an evacuated silica glass capsule lined with silver foil. A polycrystalline specimen of magnesioferrite $(\approx 3 \mathrm{~mm}$ in diameter and $2.316(3) \mathrm{mm}$ in length) was hot-pressed in a gold capsule at $950^{\circ} \mathrm{C}$ and $5 \mathrm{GPa}$, in a uniaxial split-sphere Kawai-type apparatus. The physical properties of this hot-pressed polycrystalline sample were characterized by scanning electron microscopy (SEM), density measurements, and Rietveld structure refinements. Chemical analysis of the initial powdered spinel sample shows that it is stoichiometric and additional details are given elsewhere (Antao et al. 2005b). Using the Archimedes method, the experimentally determined bulk density of the specimen was $4.554(5) \mathrm{g} \mathrm{cm}^{-3}$ at room temperature. The calculated density for magnesioferrite is $\approx 4.491 \mathrm{~g} / \mathrm{cm}^{3}$ at room temperature. Minor silver and gold impurities, acquired during sample synthesis, were observed in SEM micrographs and could give rise to a slightly higher bulk density for magnesioferrite.

In cubic spinels of formula $\mathrm{AB}_{2} \mathrm{O}_{4}$ ( $\mathrm{A}$ and $\mathrm{B}$ are cations, $\mathrm{O}$ is oxygen), the $\mathrm{A}$ and $\mathrm{B}$ cations can distribute themselves between tetrahedral and octahedral sites and the following general formula maybe written: ${ }^{\mathrm{iv}}\left[\mathrm{A}_{1-x} \mathrm{~B}_{x}\right]^{\mathrm{vi}}\left[\mathrm{A}_{x / 2} \mathrm{~B}_{1-x /}\right.$ $\left.{ }_{2}\right]_{2} \mathrm{O}_{4}$, where the variable $x$ is referred to as the "inversion parameter" and defines the state of order. This $x$ is the fraction of B cation on the tetrahedral site. In magnesioferrite, $x$ ranges from 1 for fully ordered inverse spinel to $2 /$ 3 for fully disordered state. Fully ordered normal spinels have $x=0$. Pressure enhances order in magnesioferrite, while $T$ enhances disorder. If the $T$ is sufficiently high, redistribution of the cations in spinel to an equilibrium state for that particular pressure and temperature will occur.

From in situ X-ray powder diffraction experiments at $5 \mathrm{GPa}$, the cation inversion parameter, $x$, was measured as $\sim 0.9$ on heating to $857^{\circ} \mathrm{C}$; this value was quenched in on cooling to $347^{\circ} \mathrm{C}$ (Antao et al. 2005a). Rietveld structure refinements using a small amount of sample (cut and powdered) from other hot-pressed pellets synthesized between 6 and $8 \mathrm{GPa}$ and temperatures between 900 and $1,000^{\circ} \mathrm{C}$ revealed an order parameter ranging from $x=0.91$ to 0.93 . Because the sample used in this study was hot-pressed at $5 \mathrm{GPa}$ and $950^{\circ} \mathrm{C}$, we can assume that the initial sample had $x \sim 0.9$, which was quenched in on cooling during synthesis.

At room pressure, the thermal barrier to cation redistribution in magnesioferrite is overcome by $600^{\circ} \mathrm{C}$, where an equilibrium cation distribution is obtained (Antao et al. 2005b). In this study, we report results from high-temperature ultrasonic experiments carried out at $300 \mathrm{MPa}$, and up to $550^{\circ} \mathrm{C}$, so we expect the state of cation disorder to be the same at all temperatures to $550^{\circ} \mathrm{C}$, and thus any anomalies observed must be due to effects other than cation disorder.

High-temperature ultrasonic interferometry

Ultrasonic measurements were performed by the phase comparison method (Jackson and Niesler 1982; Niesler and Jackson 1989), which provides high precision (within $0.1 \%$ ) and a substantial amount of redundancy based on determination of the elastic wave travel-time for each interference extremum across a wide range of carrier frequencies. Ultrasonic data were collected at $300 \mathrm{MPa}$ argon confining pressure and from 20 to $700^{\circ} \mathrm{C}$ on a polycrystalline magnesioferrite sample. The use of dual mode transducers allowed the simultaneous measurement of travel-times for both $\mathrm{P}$ and $\mathrm{S}$ waves under identical experimental conditions. A hardened-steel and alumina buffer rod combination, along with the sample in a $\mathrm{NaCl}$ cup were contained in a thin-walled steel sleeve. One-micron-thick layers of gold foil were used at the interfaces within the acoustic path to provide optimal mechanical coupling. The temperature, $T$, was measured with an R-type thermocouple located within a jacketed hollow alumina assembly inserted through the opposite end of the cylindrical pressure vessel. Two heating and one cooling cycles (hereafter denoted as $h$ or $c$ with a number) were carried out at about $300 \mathrm{MPa}$. Signal quality was continuously monitored during these cycles (Fig. 1). The heating and cooling rate was $10^{\circ} \mathrm{C} / \mathrm{min}$, and the sample was held at the different temperatures for variable amounts of time to improve signal quality. In the first cycle, while no data were collected, the sample was heated to $400^{\circ} \mathrm{C}$ and held at that $T$ for 3 days under pressure to establish optimal contact across the gold foils embedded within the acoustic path. Data were collected on cooling back to room $T(1 c$; Fig. 2). In a second cycle, $2 h$, data were collected on heating to $700^{\circ} \mathrm{C}$ (with a 

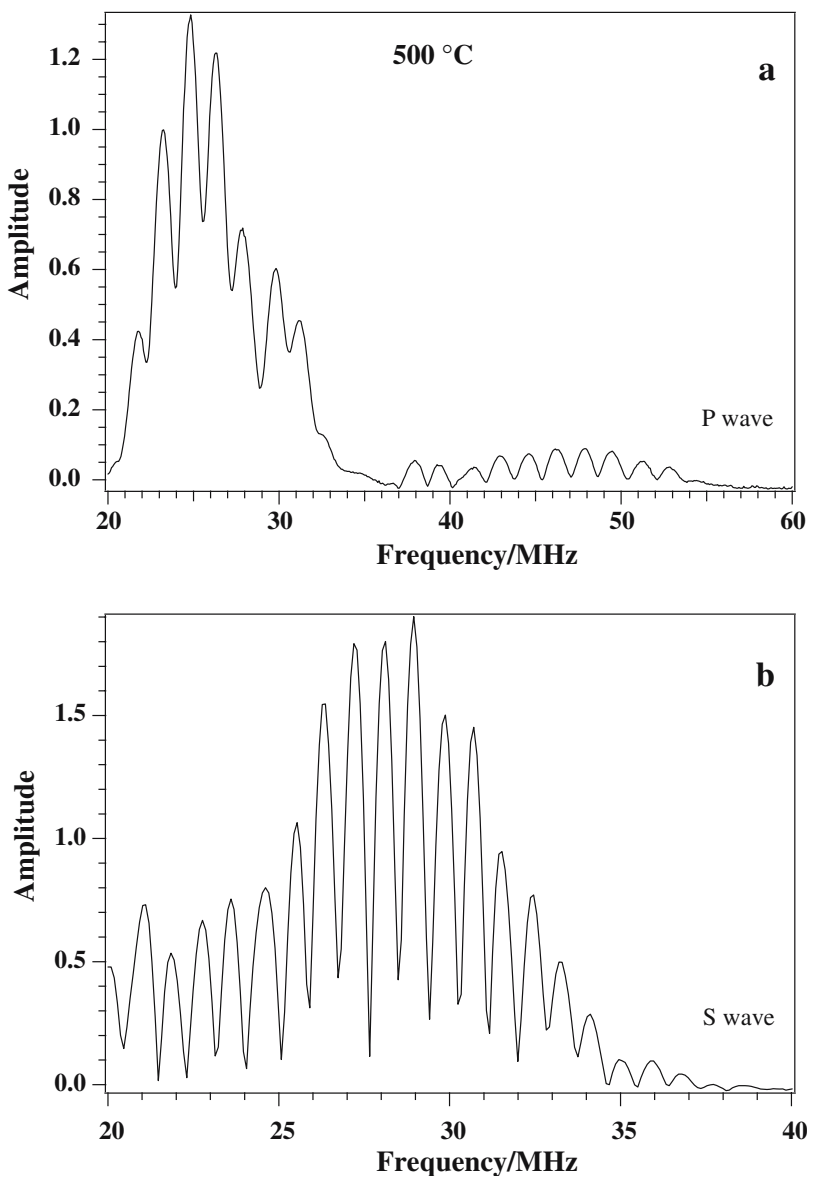

Fig. 1 Representative interference patterns resulting from overlap of the echoes returning to the transducer from the near and far ends of the sample gold-bonded to the end of the acoustic buffer rod. Average travel-times were determined from the frequencies of the deepest minima at carrier frequencies above 40 and $24 \mathrm{MHz}$ for $\mathrm{P}$ and $\mathrm{S}$ waves, respectively

halt at $400^{\circ} \mathrm{C}$ for $12 \mathrm{~h}$ ). The average travel-times (calculated for all interference minima with carrier frequencies above 40 and $24 \mathrm{MHz}$ for $\mathrm{P}$ and $\mathrm{S}$ waves, respectively) were converted into wave velocities using the measured length of the specimen at ambient conditions adjusted for thermal expansion using the data of Antao et al. (2005b).

Adjustment of specimen length for temperature effect

The velocities have been obtained after estimating the length of the specimen at different temperatures using the thermal-expansion data from Antao et al. (2005b) and the expression:

$\frac{a_{T} l_{0}}{a_{0}}=l_{T}$,

where $a_{0}$ and $l_{0}$ are the unit-cell parameter and the measured initial length, respectively; $a_{T}$ and $l_{T}$ are the estimated cell parameter and length at any temperature, $T$.

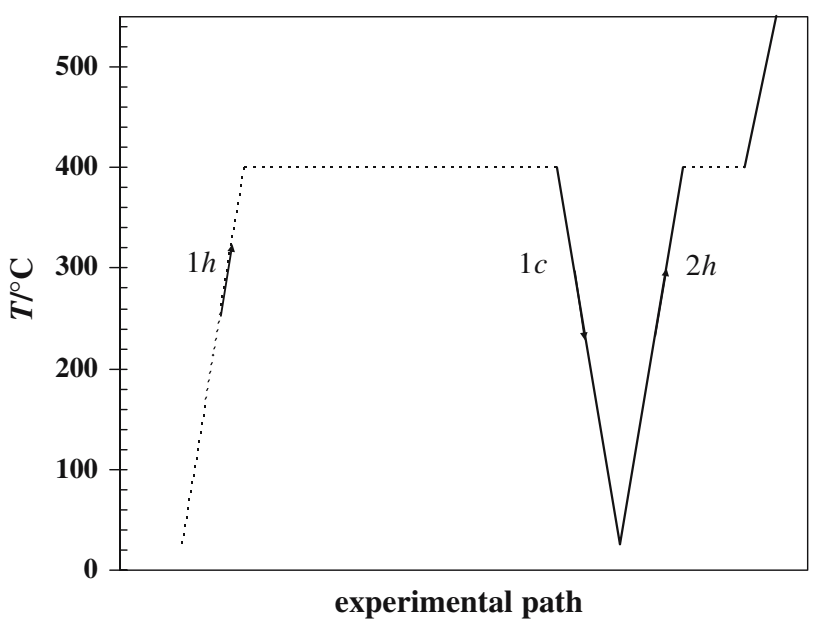

Fig. 2 Schematic experimental path at about $300 \mathrm{MPa}$. 1 The sample was heated to $400^{\circ} \mathrm{C}\left(1 \mathrm{~h}\right.$; and held at $400^{\circ} \mathrm{C}$ for 3 days) and data were collected on cooling, $1 \mathrm{c} .2 \mathrm{~h}$, data were collected on heating to $700^{\circ} \mathrm{C}$ (with a halt at $400^{\circ} \mathrm{C}$ for $12 \mathrm{~h}$ ), however, data only up to $550^{\circ} \mathrm{C}$ are reported in this paper

The linear thermal-expansivity data for magnesioferrite from Antao et al. (2005b) were obtained by fitting all the cell data simultaneously to the expression:

$a(T)=a_{\operatorname{Tr}} \exp \left[\int_{\operatorname{Tr}}^{T} \alpha_{a}(T) \mathrm{d} T\right]$,

where $a(T)$ is the cell parameter at any temperature $T, a_{\mathrm{Tr}}$ is the cell parameter at reference $T$, (usually room $T$ ), and $\alpha_{a}(T)$ is a polynomial expression for the linear-thermal expansion coefficient: $\alpha_{a}(T)=\alpha_{0}+\alpha_{1} T+\alpha_{2} T^{-2}$. In the fitting procedure, $a_{\operatorname{Tr}}$ was set as a variable because the initial cell parameter for the "as synthesized sample" cannot be used as the initial cell parameter for the hotpressed sample. The degree of order quenched in the hotpressed sample will change the cell parameter by a minor amount. Ignoring the quadratic term, for the range 28 $982^{\circ} \mathrm{C}$ and using both heating and cooling data from Antao et al. (2005b), the values: $\alpha_{0}=9.68( \pm 0.76) \times 10^{-6} \mathrm{k}^{-1}$ and $\alpha_{1}=6.98( \pm 3.57) \times 10^{-10} \quad \mathrm{k}^{-2}$ were obtained with $a_{\mathrm{Tr}}=8.3949(8) \AA$ at room $T$. This $a_{\operatorname{Tr}}$ was used as the value for $a_{0}$ in Eq. 1 .

Using the measured travel times $t_{(\mathrm{P}, \mathrm{S})}$, the velocities for $\mathrm{P}\left(V_{\mathrm{P}}\right)$ and $\mathrm{S}\left(V_{\mathrm{S}}\right)$ waves in magnesioferrite were obtained from the equation:

$V_{(\mathrm{P}, \mathrm{S})}=2 l_{T} / t_{(\mathrm{P}, \mathrm{S})}$.

The length $\left(l_{T}\right)$ of the sample at the various temperatures was estimated using Eqs. 1 and 2, and the travel-time $\left(t_{T}\right)$ was obtained directly from the experiment. By combining 
Table 1 Room $T$ velocities, moduli, and derivatives for magnesioferrite

\begin{tabular}{lllllllll}
\hline$T /{ }^{\circ} \mathrm{C}$ & $V_{\mathrm{P}} /(\mathrm{km} / \mathrm{s})$ & $V_{\mathrm{S}} /(\mathrm{km} / \mathrm{s})$ & $K_{0} / \mathrm{GPa}$ & $G_{0} / \mathrm{GPa}$ & $\left(\partial K_{\mathrm{S}} / \partial T\right)_{P} / \mathrm{GPa} \mathrm{K}^{-1}$ & $(\partial G / \partial T)_{P} / \mathrm{GPa} \mathrm{K} \mathrm{K}^{-1}$ & $\rho /\left(\mathrm{g} / \mathrm{cm}^{3}\right)$ & $l_{0} /(\mathrm{mm})$ \\
\hline 22 & $7.885(11)$ & $4.193(6)$ & $176.3(7)$ & $80.1(2)$ & $-0.032(3)$ & $-0.012(1)$ & $4.554(5)$ & $2.316(3)$
\end{tabular}

Derivatives are obtained from $(1 c, 2 h)$ datasets for $T \leq 350^{\circ} \mathrm{C}$ (see text)

Table 2 Travel-times, estimated lengths, velocities, moduli, and densities for magnesioferrite

\begin{tabular}{cllllllll}
\hline$T /{ }^{\circ} \mathrm{C}$ & $t_{\mathrm{P}} / \mu \mathrm{s}$ & $t_{\mathrm{S}} / \mu \mathrm{s}$ & $l_{T} /(\mathrm{mm})$ & $V_{\mathrm{P}} /(\mathrm{km} / \mathrm{s})$ & $V_{\mathrm{S}} /(\mathrm{km} / \mathrm{s})$ & $K_{\mathrm{S}} / \mathrm{GPa}$ & $G / \mathrm{GPa}$ & $\rho /\left(\mathrm{g} / \mathrm{cm}^{3}\right)$ \\
\hline $1 c$ & & & & & & & \\
350 & $0.6038(3)$ & $1.1308(3)$ & $2.324(3)$ & $7.698(11)$ & $4.111(5)$ & $165.6(6)$ & $76.2(2)$ & $4.510(5)$ \\
300 & $0.6007(5)$ & $1.1264(4)$ & $2.323(3)$ & $7.734(12)$ & $4.124(6)$ & $167.7(7)$ & $76.8(2)$ & $4.517(5)$ \\
250 & $0.5981(4)$ & $1.1227(4)$ & $2.322(3)$ & $7.763(11)$ & $4.136(6)$ & $169.4(7)$ & $77.4(2)$ & $4.524(5)$ \\
200 & $0.5960(4)$ & $1.1188(3)$ & $2.320(3)$ & $7.787(11)$ & $4.148(5)$ & $170.7(7)$ & $78.0(2)$ & $4.530(5)$ \\
100 & $0.5912(3)$ & $1.1114(3)$ & $2.318(3)$ & $7.842(11)$ & $4.172(6)$ & $174.0(7)$ & $79.1(2)$ & $4.544(5)$ \\
22 & $0.5876(2)$ & $1.1048(3)$ & $2.316(3)$ & $7.885(11)$ & $4.193(6)$ & $176.3(7)$ & $80.1(2)$ & $4.554(5)$ \\
$2 h$ & & & & & & \\
100 & $0.5911(2)$ & $1.1115(3)$ & $2.318(3)$ & $7.843(10)$ & $4.171(6)$ & $174.1(7)$ & $79.1(2)$ & $4.544(5)$ \\
150 & $0.5936(2)$ & $1.1152(3)$ & $2.319(3)$ & $7.814(10)$ & $4.159(5)$ & $172.4(6)$ & $78.5(2)$ & $4.537(5)$ \\
252 & $0.5982(3)$ & $1.1230(3)$ & $2.322(3)$ & $7.763(11)$ & $4.135(5)$ & $169.5(7)$ & $77.3(2)$ & $4.523(5)$ \\
300 & $0.6006(4)$ & $1.1270(3)$ & $2.323(3)$ & $7.734(11)$ & $4.122(5)$ & $167.9(7)$ & $76.8(2)$ & $4.517(5)$ \\
350 & $0.6036(3)$ & $1.1304(3)$ & $2.324(3)$ & $7.701(11)$ & $4.112(5)$ & $165.8(6)$ & $76.3(2)$ & $4.510(5)$ \\
400 & $0.6020(2)$ & $1.1284(3)$ & $2.325(3)$ & $7.725(10)$ & $4.121(5)$ & $166.8(6)$ & $76.5(2)$ & $4.503(5)$ \\
450 & $0.6044(2)$ & $1.1330(3)$ & $2.326(3)$ & $7.698(10)$ & $4.107(5)$ & $165.4(6)$ & $75.8(2)$ & $4.497(4)$ \\
500 & $0.6075(5)$ & $1.1391(5)$ & $2.328(3)$ & $7.663(12)$ & $4.087(6)$ & $163.7(7)$ & $75.0(2)$ & $4.490(4)$ \\
550 & $0.6107(5)$ & $1.1469(3)$ & $2.329(3)$ & $7.627(12)$ & $4.061(5)$ & $162.2(6)$ & $73.9(2)$ & $4.483(4)$ \\
\hline
\end{tabular}

Moduli were obtained using thermal-expansion data from Antao et al. (2005b) and the experimentally determined bulk density $(\rho=4.554(5) \mathrm{g}$ $\mathrm{cm}^{-3}$ ). The uncertainties in $K_{S}$ and $G$ were obtained by error propagation and based on a $0.1 \%$ uncertainty in density

a The sample length only at room temperature was measured [2.316(3) $\mathrm{mm}$ ] and the other sample lengths were calculated using Eqs. 1 and 2

the measured bulk density at ambient conditions with the thermal-expansion data from Antao et al. (2005b), the elastic bulk $\left(K_{\mathrm{S}}\right)$ and shear $(G)$ moduli were calculated from the $\mathrm{P}$ and $\mathrm{S}$ wave velocities.

\section{Results}

Measured elastic wave travel-times, calculated wave velocities, and elastic moduli are presented as functions of temperature in Tables 1,2 and Fig. 3. There is a generally smooth and consistent trend of increasing travel-times from 22 to $350^{\circ} \mathrm{C}$; the trends for velocities and elastic moduli are also linear in this temperature range. From cycles $1 c$ and $2 h$ between 22 and $350^{\circ} \mathrm{C}$, we obtain $\partial K_{\mathrm{S}} / \partial T$ and $\partial G / \partial T$ values of $-0.032(3)$ and $-0.012(1) \mathrm{GPa} \mathrm{K}^{-1}$, respectively. These derivatives are based on least-squares fits to the variation of modulus $\left(K_{\mathrm{S}}, G\right)$ with temperature using thermal-expansion data from Antao et al. (2005b) and the experimentally determined bulk density, $\rho=4.554(5) \mathrm{g} \mathrm{cm}^{-3}$ (Tables 1 , 2).

A significant discontinuity between 350 and $400^{\circ} \mathrm{C}$ is evident in the second heating cycle for all properties (Fig. 3). Between 350 and $400^{\circ} \mathrm{C}$, there are abrupt increases in both the $\mathrm{P}$ and $\mathrm{S}$ wave velocities of 1.0 and $0.7 \%$, respectively. For both the bulk and shear moduli data, the change at the discontinuity is $1.4 \%$. For the elasticity data between 400 and $550^{\circ} \mathrm{C}$, the $K_{\mathrm{S}}-T$ slope [$\left.0.031(5) \mathrm{GPa} \mathrm{K}^{-1}\right]$ is almost unchanged from that at lower temperatures, whereas the $G-T$ slope is steeper [$0.017(1) \mathrm{GPa} \mathrm{K}^{-1}$ ]. Below $360^{\circ} \mathrm{C}$, a close consistency is observed between results obtained during the $1 c$ cooling cycle and the subsequent heating cycle, $2 h$. Above $550^{\circ} \mathrm{C}$ in cycle $2 h$, the amplitude of the acoustic echoes decreases dramatically; this behavior could be related to either cation mobility or irreversible changes in the sample. These effects are being investigated further and will be reported in a separate communication. 

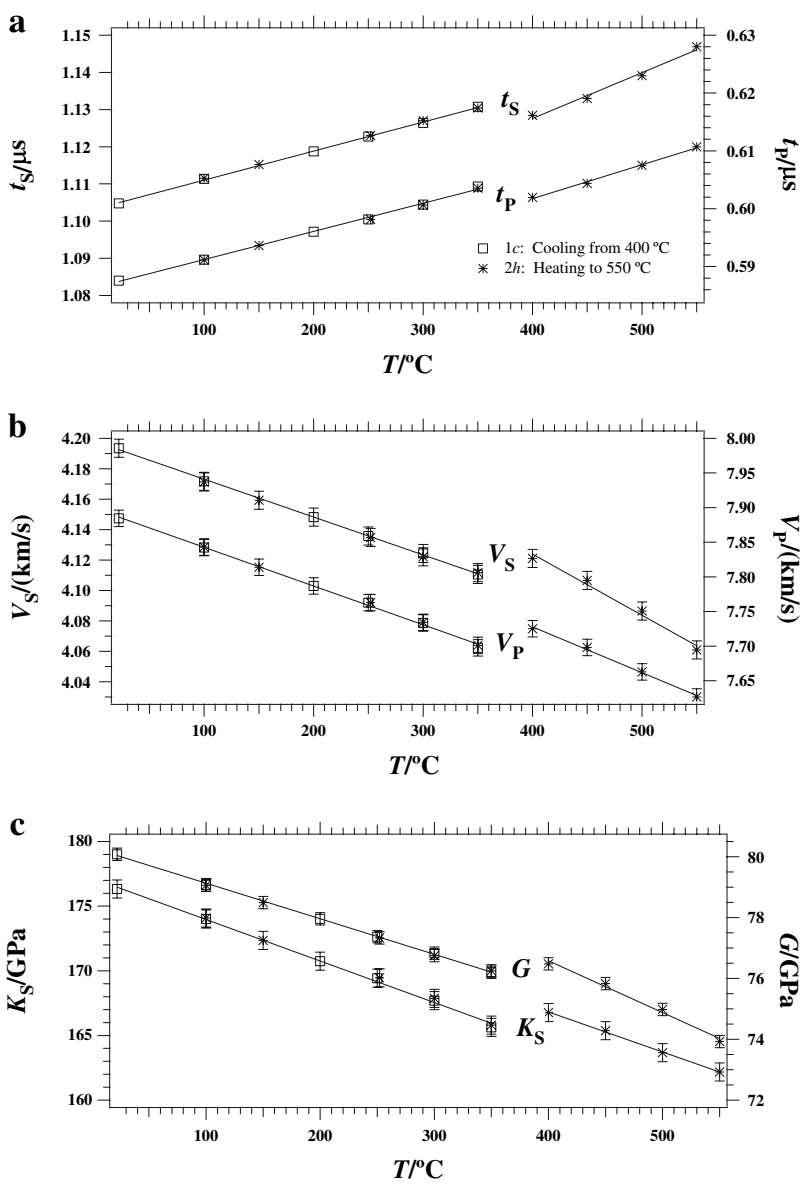

Fig. 3 Variations in elastic data versus temperature for magnesioferrite held at a constant pressure of $300 \mathrm{MPa}$. a Travel-times for $\mathrm{S}$ waves $\left(t_{\mathrm{S}}\right)$ and $\mathrm{P}$ waves $\left(t_{\mathrm{P}}\right)$, b velocities for $\mathrm{S}$ waves $\left(V_{\mathrm{S}}\right)$ and $\mathrm{P}$ waves $\left(V_{\mathrm{P}}\right)$, and $\mathbf{c}$ bulk modulus $\left(K_{\mathrm{S}}\right)$, and shear modulus $(G)$. Error bars are not seen if smaller than the symbols. A discontinuity is observed near the magnetic transition, $T_{\mathrm{c}} \approx 360^{\circ} \mathrm{C}$. Linear trend lines are fitted to the data above and below $T_{c}$

\section{Discussion}

The recent work of Antao et al. (2005b) using thermogravimetric analysis in the presence of a magnetic field detected the Curie transition between the low-temperature ferrimagnetic and high-temperature paramagnetic phases at $\sim 360^{\circ} \mathrm{C}$. The consistent, reversible linear temperature dependence of travel-times, derived wave speeds, and moduli for cycles $1 c$ and $2 h$, below $350^{\circ} \mathrm{C}$ suggest that both the magnetic condition of the specimen and its cation configuration remain unchanged. In order to change the cation configuration in magnesioferrite at room $P$, temperatures greater than $600^{\circ} \mathrm{C}$ are required (Antao et al. 2005b).

The discontinuities in travel-times, wave velocities and moduli observed between 350 and $400^{\circ} \mathrm{C}$ are attributed to changes in the elastic properties of magnesioferrite due to the magnetic Curie transition. Such effects have been

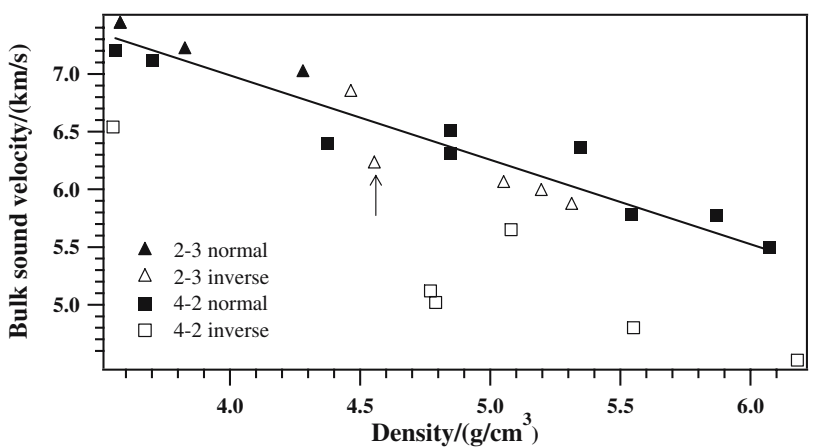

Fig. 4 Bulk sound velocity versus density for oxide spinels of 2-3 and 4-2 cation valences for both normal and inverse degrees of cation order. Data are from the tabulations of Liebermann (1975) and Liebermann et al. (1977), supplemented by recent data from $\mathrm{Li}$ (2003), Sinogeikin et al. (2003), and Reichmann and Jacobsen (2004, 2006). The arrow points to magnesioferrite data from this study. Solid line is a linear fit to all data points excluding the 4-2 inverse spinels

observed previously in ferrite spinels, $3 \mathrm{~d}$-transition element oxides and hematite [see data and references cited in Liebermann and Banerjee (1971) and Liebermann and Remsberg (1988)].

The bulk sound velocity $\left[V_{\phi}=\left(K_{\mathrm{S}} / \rho\right)^{1 / 2}\right]$ versus density or mean atomic weight, $\bar{M}$, for magnesioferrite at room $T$, plots close to the isostructural trend observed for 2-3 normal and inverse spinels and 4-2 normal spinels (Fig. 4; also see Figs. 10 and 11 in Liebermann et al. 1977). The 4-2 inverse spinels, $\mathrm{TiMg}_{2} \mathrm{O}_{4}$ and $\mathrm{SnMg}_{2} \mathrm{O}_{4}$ for example, are distinguished from their 4-2 normal counterparts by having significantly lower velocities for a given density (Liebermann et al. 1977). The value of the product $V_{\phi} \bar{M}^{1 / 2}=33.3 \mathrm{~km} / \mathrm{s} \mathrm{g}^{1 / 2}$ for magnesioferrite, falls within the range of $33-35 \mathrm{~km} / \mathrm{s}$ g specified by Liebermann et al. (1977) for 2-3 and 4-2 normal spinels.

Acknowledgments The experimental work was performed in the high-pressure laboratory at the Australian National University with the assistance of Craig Saint and Lara Weston under funding from the Australian Research Council (LX0348106). This study was also partially supported by NSF grants EAR-0510501 to JBP and NSFINT 0233849 to RCL for a collaborative research program with the Australian National University.

\section{References}

Antao SM, Hassan I, Crichton W, Parise JB (2005a) Effects of high pressure and high temperature on cation ordering in magnesioferrite, $\mathrm{MgFe}_{2} \mathrm{O}_{4}$, using in situ synchrotron X-ray powder diffraction up to $1,430 \mathrm{~K}$ and $6 \mathrm{GPa}$. Am Mineral 90:1500-1505

Antao SM, Hassan I, Parise JB (2005b) Cation ordering in magnesioferrite, $\mathrm{MgFe}_{2} \mathrm{O}_{4}$, to $982^{\circ} \mathrm{C}$ using in situ synchrotron X-ray powder diffraction. Am Mineral 90:219-228

Hazen RM, Yang HX (1999) Effects of cation substitution and orderdisorder on $\mathrm{P}-\mathrm{V}-\mathrm{T}$ equations of state of cubic spinels. Am Mineral 84:1956-1960 
Jackson I, Niesler H (1982) The elasticity of periclase to $3 \mathrm{GPa}$ and some geophysical implications. In: Akimoto S, Manghnani MH (eds) High-pressure research in geophysics. Centre for academic publications, Japan, pp 93-113

Li B (2003) Compressional and shear wave velocities of ringwoodite $\gamma-\mathrm{Mg}_{2} \mathrm{SiO}_{4}$ to $12 \mathrm{GPa}$. Am Mineral 88:1312-1317

Li L, Carrez P, Weidner DJ (2007) Effect of cation ordering and pressure on spinel elasticity by ab initio simulation. Am Mineral 92:174-178

Liebermann RC (1975) Elasticity of olivine $(\alpha)$, beta $(\beta)$, and spinel $(\gamma)$ polymorphs of germanates and silicates. Geophys J R Astron Soc 42:899-929

Liebermann RC, Banerjee SK (1971) Magnetoelastic interactions in hematite-implications for geophysics. J Geophys Res 76:27352757

Liebermann RC, Remsberg AR (1988) Elastic behavior of magnetic oxides from acoustic and static compression studies. Phys Earth Planet Inter 51:86-92

Liebermann RC, Jackson I, Ringwood AE (1977) Elasticity and phase equilibria of spinel disproportionation reactions. Geophys J R Astron Soc 50:553-586

Niesler H, Jackson I (1989) Pressure derivatives of elastic wave velocities from ultrasonic interferometic measurements on jacketed polycrystals. J Acoustic Soc Am 86:1573-1585
O'Neill HSC, Wall VJ (1987) The olivine ortho-pyroxene spinel oxygen geobarometer, the nickel precipitation curve, and the oxygen fugacity of the Earth's upper mantle. J Petrol 28:11691191

Reichmann HJ, Jacobsen SD (2004) High-pressure elasticity of a natural magnetite crystal. Am Mineral 89:1061-1066

Reichmann HJ, Jacobsen SD (2006) Sound velocities and elastic constants of $\mathrm{ZnAl}_{2} \mathrm{O}_{4}$ spinel and implications for spinel-elasticity systematics. Am Mineral 91:1049-1054

Sack RO (1982) Spinels as petrogenetic indicators-activity-composition relations at low-pressures. Contrib Mineral Petrol 79:169186

Sinogeikin SV, Bass JD, Katsura T (2003) Single-crystal elasticity of ringwoodite to high pressures and high temperatures: implications for $520 \mathrm{~km}$ seismic discontinuity. Phys Earth Planet Inter 136:41-66

Sturhahn W, Jackson JM, Lin JF (2005) The spin state of iron in minerals of Earth's lower mantle. Geophys Res Lett 32:L12307. doi:10.1029/2005GL022802 